\title{
Effectiveness of chemotherapy in advanced differentiated thyroid cancer: a systematic review
}

\author{
Ana Albero', Juliana Ester Lopéz ${ }^{2}$, Alberto Torres ${ }^{3}$, Luis de la Cruz ${ }^{1}$ and Tomas Martín ${ }^{3}$ \\ 'Department of Oncology, University Hospital 'Virgen Macarena', Seville, Spain \\ ${ }^{2}$ Andalusian Agency for Health Technology Assessment (AETSA), Regional Ministry of Health and Social Welfare, \\ Seville, Spain \\ ${ }^{3}$ Department of Endocrinology and Nutrition, University Hospital 'Virgen Macarena', Avenue Dr Fedriani s/n. 41003 \\ Seville, Spain
}

Correspondence should be addressed to T Martin

Email

tmartin@cica.es

\begin{abstract}
In differentiated thyroid carcinoma refractory to radioactive iodine (CDT-RTI), chemotherapy has been considered for decades to be the only systemic therapy with palliative purpose. Phase II studies assessing the efficacy of different chemotherapy outlines have been published. Nevertheless, phase III studies in these tumours have not been performed. Our objective is to evaluate the effectiveness of chemotherapy in patients with CDT-RTI by a systematic review of published studies. Systematic research of the literature in Medline and Embase databases (among others) was carried out. The full texts of selected references were analysed by two independent reviewers and then assessed for risk of bias in each study. We also extracted data using specifically designed questionnaires. Later, a qualitative synthesis of results was performed and pooled data were calculated. We found that 16 studies with 473 patients published in the last 40 years were included out of 509 identified references in databases. Thirteen studies (176 patients) included data on response to treatment and histology. Four studies included 70 patients only with well-differentiated non-medullary tumours. Response rate (RR) was $22.1 \%$ (0-57\%) for 13 studies, 25\% for the 176 patients and $27.1 \%$ for the 70 patients, with $2.5,3.4$ and $2.8 \%$ complete responses respectively. Survival times could not be assessed or pooled due to the lack of data and heterogeneity of the studies, and was determined to have a high risk of bias. Although it has not been possible to find solid evidence about the efficacy of chemotherapy, the results shown indicate that it may have some effectiveness, although this should be proven with well-designed studies using modern drugs.
\end{abstract}

\section{Key Words}

- advanced thyroid cancer

- overall survival

- chemotherapy

- adriamycin

- radioactive iodine refractory thyroid cancer

\section{Introduction}

Differentiated carcinoma accounts for 95\% of all the cases of thyroid cancer (Cooper et al. 2009). These tumours grow from aberrant follicular cells and are classified histologically as papillary, follicular (including Hürtle's cells carcinoma) or poorly differentiated. Generally, they are treated effectively with surgery, radioactive iodine (RTI) and suppressive therapy with L-thyroxine. Nevertheless, $7-23 \%$ of patients will develop metastases, two-thirds of whom will become resistant to radioactive iodine treatment (Durante et al. 2006). In these patients, the median

Published by Bioscientifica Ltd.
Endocrine-Related Cancer (2016) 23, R71-R84 
survival at 10 years can be as low as $25-42 \%$, especially when bone metastases are present (Durante et al. 2006, Pacini et al. 2006, Cooper et al. 2009). Differentiated thyroid carcinoma refractory to radiodine (CDT-RTI) is not considered to be responsive to chemotherapy generally, although for decades this has been considered to be the only systemic treatment with a palliative purpose. Several cytostatics have been tested in small studies with different results, but of all of them adriamycin in monotherapy has been traditionally considered the standard therapy (Gottlieb et al. 1972, Leeper \& Shimaoka 1980, Poster et al. 1981, Schlumberger 1999, Sherman 2010).

In the last decade, the use of new agents has been proposed, which have demonstrated to be relatively useful in different grades of this kind of cancer (Cohen et al. 2008, Sherman et al. 2008, 2011, Schlumberger et al. 2009, Bible et al. 2010, Carr et al. 2010, Cabanillas et al. 2012, National Comprehensive Cancer Network 2013), although multiple side effects of their use have been described (hypertension, bleeding, feet-hand syndrome, intense asthenia, weight loss, anaemia) (Illouz et al. 2014). Among all of them, sorafenib has been approved by the European Medicines Agency (EMEA) and lenvatinib will possibly be validated in due course. Both have been approved by the Food and Drug Administration (FDA) for CDT-RTI (Brose et al. 2014, Schlumberger $e$ tal. 2015), due to the fact that they achieve significantly higher stabilization of the disease and progression-free survival (PFS), although this has only been compared with placebo. Nonetheless, neither of them has displayed evidence of a beneficial effect on survival, probably due to the cross-over allowed in these studies. Also, often side effects of the long-term treatment result in a deterioration of the quality of life of these patients (which is not too damaged initially). Therefore, a thorough assessment of the efficacy and iatrogenic effects of sorafenib and lenvatinib is necessary to preserve the clinical benefit of these therapies.

The objective of this work is to perform a systematic review of the published studies of the effectiveness of chemotherapy, with special emphasis on analysing response rates and overall survival (OS) of patients with well differentiated and non-medullary thyroid tumours, in an advanced stage and resistant to radioactive iodine treatment, symptomatic or on progression of the disease, treated with diverse chemotherapy schemes.

\section{Methodology}

A systematic search of the literature using structured search strategies, according to population format, intervention, comparison and results-outcomes (PICO) was carried out in order to identify the main relevant studies related to the effectiveness of chemotherapy as palliative treatment for well differentiated non-medullary thyroid cancer. Searches were performed from the opening of databases until 1 June, 2014. The development of search strategies was specific for each of the consulted databases: Medline (including PRE-MEDLINE by PUBMED and PUBMED Health), SCOPUS, EMBASE (Evidence Based Medicine) and the Cochrane Library. For the searches in other databases, such as the Centre for Reviews and Dissemination (CRD that includes the databases of DARE, HTA and NHS EED), Emergency Care Research Institute (ECRI) and metasearchers of SCOPUS, open strategies were used using free text. Websites of scientific societies such as the American Thyroid Association (ATA) were also consulted. Additionally, reference lists of the final selection of articles were checked manually to identify other relevant papers. The search was not limited with respect to language or type of study and it was carried out from 1974 onwards, because from the publication of the work of Gottlieb \& Hill (1974), adriamycin was considered the standard chemotherapy regimen. Abstracts for which we could not locate a full-text article were excluded, as were publications in a language other than English, French or German. Disagreements were resolved by consensus.

Titles and abstracts of all retrieved articles were scanned for inclusion by two reviewers with reference to a third reviewer when there was any doubt about their eligibility. When information given in title/abstracts indicated that the study: i) included patients with thyroid carcinoma and ii) included patients subjected to palliative chemotherapy, then the article was considered for the further examination. Furthermore, if there was doubt regarding inclusion on the basis of the title and abstract, the full article was obtained for clarification. Two independent reviewers applied stringent inclusion/exclusion criteria to full papers in order to obtain the final set of included studies.

In this way, studies (prospective and retrospective) with adult patients with diagnosis of locally advanced and non-operable, metastatic well-differentiated non-medullary thyroid carcinoma were included. Both comparative and non-comparative studies were included as were studies that analysed populations with disease in progression and treatment-resistant to radioactive iodine, particularly those that underwent palliative chemotherapy with any drug and/or drug association. Studies with 10 or fewer patients were excluded as series of cases

Published by Bioscientifica Ltd. 
with a small number of patients could show a high rate of adverse events associated with little experience of this kind of treatment. Letters to the editor, unpublished data or congress abstracts were also excluded.

Data extraction was performed using predefined data extraction forms after a detailed reading of the included full text articles, following the Preferred Reporting Items for Systematic Reviews and Meta-Analyses (PRISMA) guidelines. A critical reading was made, assessing the methodology proposed using the evaluation tool, Quality Assessment Tool for Case Series Studies proposed by the National Institutes of Health (NIH) specifically for a series of cases (https://www.nhlbi.nih.gov/health-pro/ guidelines/in-develop/cardiovascular-risk-reduction/tools/ case_series.htm) and the tool proposed by the Cochrane
Collaboration for clinical trials. In addition, a qualitative synthesis was made and pooled data (for outcomes of response rate or clinical benefit) was calculated over the total of patients by an analysis of the intention to treat and the gathering of results according to the chemotherapeutic scheme used. The survival probability was calculated with the Kaplan-Meier method when the study did not specify current survival data, but it did specify individual survival data and patient condition at the end of the follow up.

\section{Results}

As a result of the described search, 509 references were obtained that were potentially relevant and that assessed
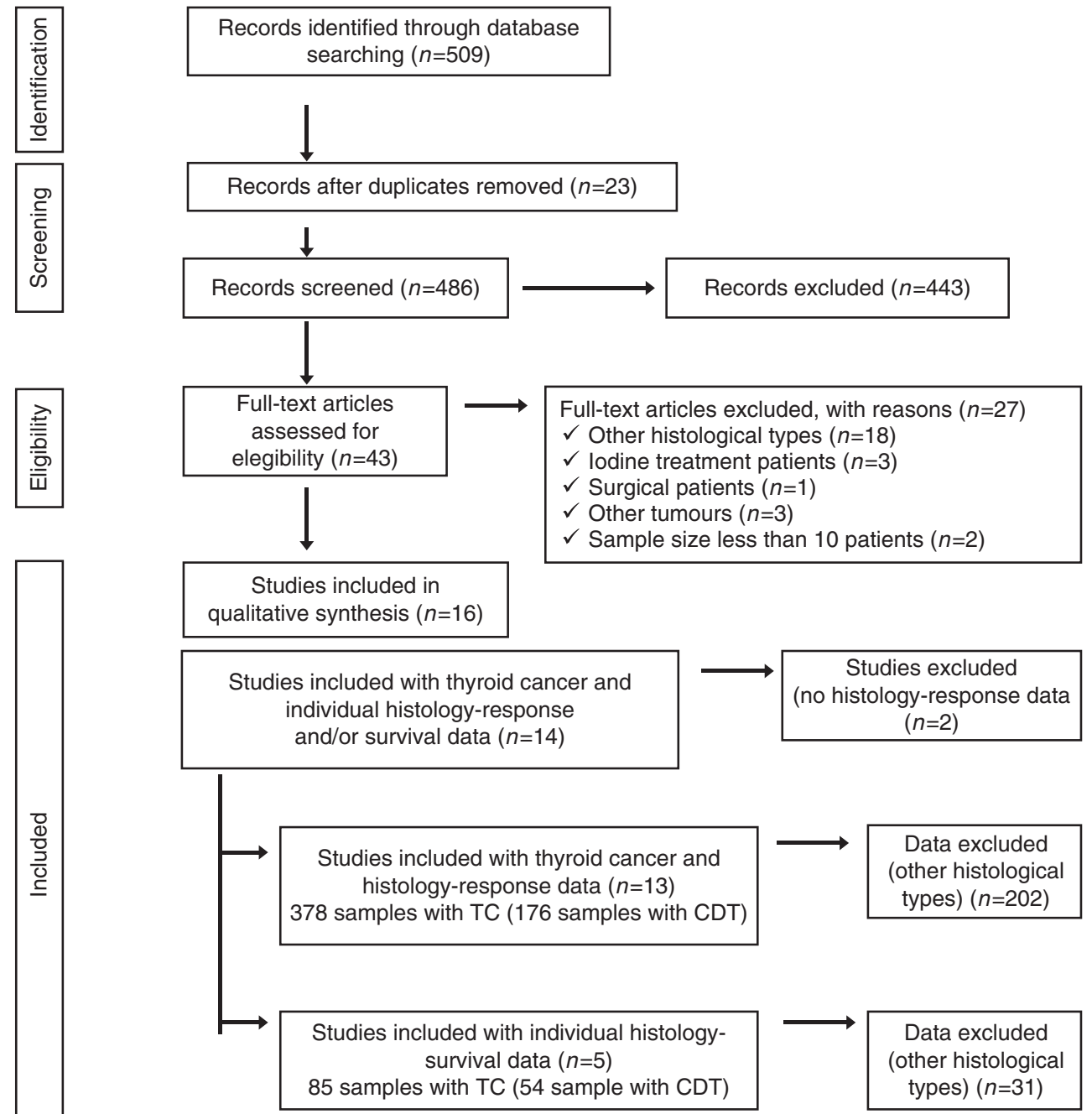

Figure 1

Flow chart of article flow through the systematic review. 
the effectiveness of different chemotherapeutic schemes as palliative treatment for patients with well-differentiated, non-medullary thyroid carcinoma. As displayed in Fig. 1, out of all the references, finally, 16 publications were included in this review (one of which included five series of patients). One was a randomized clinical trial (RCT) (Shimaoka et al. 1985), 13 were phase II studies/prospective series of cases (SC) (Gottlieb \& Hill 1974, Benker et al. 1977, Benker \& Reinwein 1983, Bukowski et al. 1983, Williams et al. 1986, Hoskin \& Harmer 1987, Schlumberger \& Parmentier 1989, Droz et al. 1990, Scherübl et al. 1990, De Besi et al. 1991, Santini et al. 2002, Argiris et al. 2008, Spano et al. 2012) and two were on retrospective SC (Matuszczyk et al. 2008, Hussein et al. 2013).
The clinical trial included was published in 1985, whereas the publication period of the series of cases ranged between 1974 and 2013. Three studies analysed the results of the treatment with adriamycin or cisplatin in monotherapy (Gottlieb \& Hill 1974, Droz et al. 1990, Matuszczyk et al. 2008), six analysed combinations of adriamycin with cisplatin \pm other drugs $(n=181)$ (Shimaoka et al. 1985, Williams et al. 1986, Droz et al. 1990, Scherübl et al. 1990, De Besi et al. 1991, Hussein et al. 2013), five studies the combinations of adriamycin which did not include cisplatin $(n=113)$ (Benker et al. 1977, Benker \& Reinwein 1983, Bukowski et al. 1983, Droz et al. 1990, Argiris et al. 2008) and another five studies analysed the results of other treatment schemes $(n=86)$

Table 1 Characteristics of studies included in the analysis

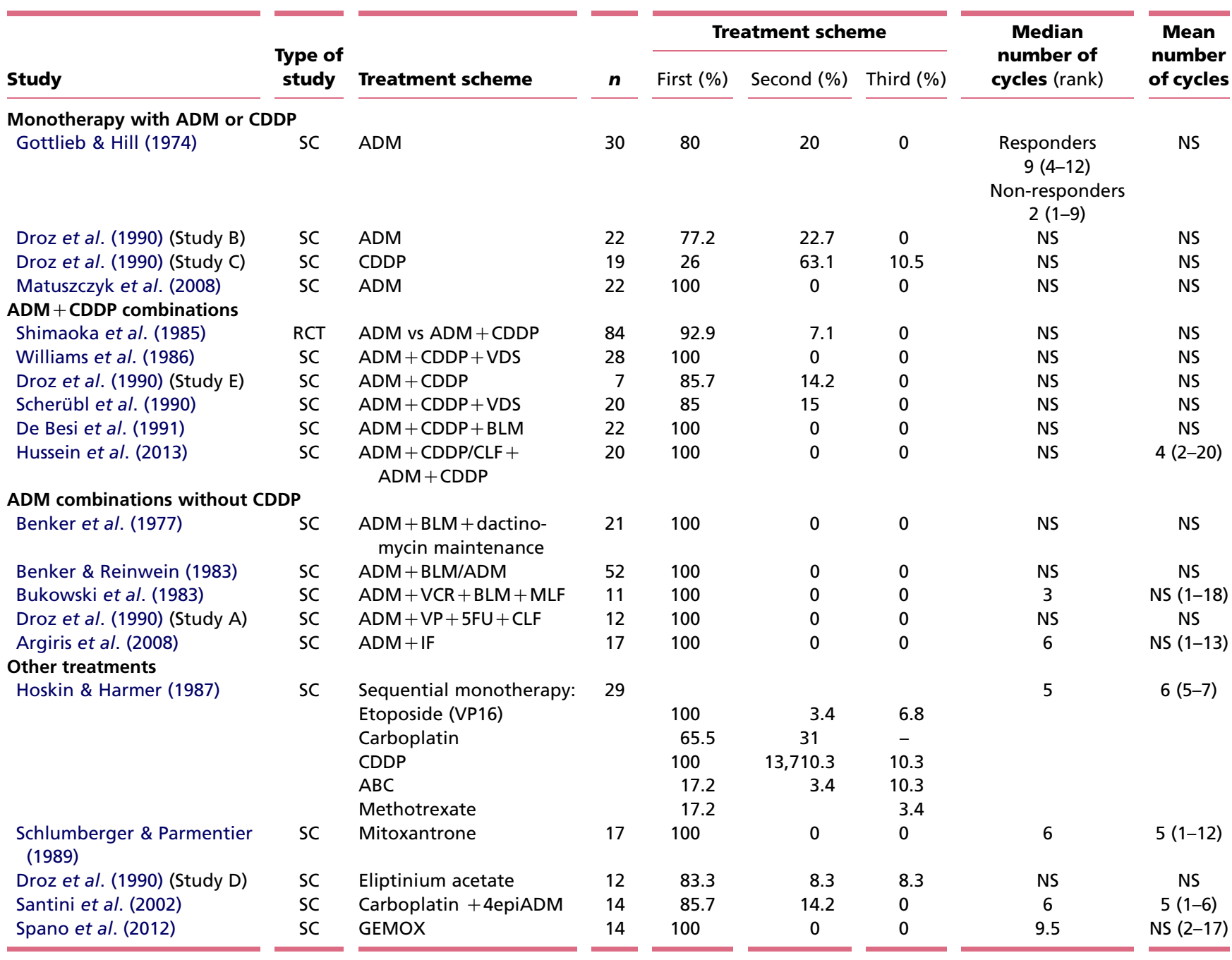

$\mathrm{RCT}$, randomized clinical trial, SC, descriptive series; ADM, adriamycin; CDDP, cisplatin; BLM, bleomycin; VDS, vindesine; IF, interferon alpha; VCR, vincristine MLF, melphalan; VP, VP-16; 5FU, 5-fluorouracil; CLF, cyclophosphamide; GEMOX, gemcitabine+oxaliplatin; ABC, adriamycin + vincristine+bleomycin; NS, not specified.

http://erc.endocrinology-journals.org DOI: 10.1530/ERC-15-0194
(C) 2016 Society for Endocrinology Printed in Great Britain
Published by Bioscientifica Ltd 


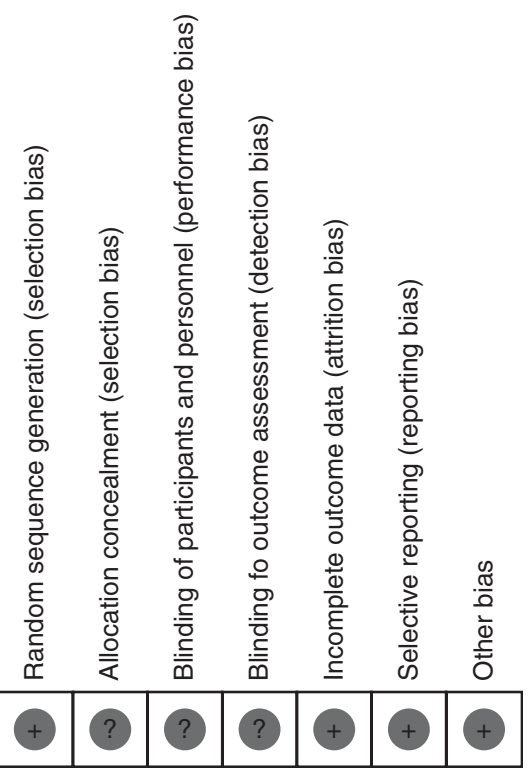

Figure 2

Summary of risks of bias in the clinical trials.

(Hoskin \& Harmer 1987, Schlumberger \& Parmentier 1989, Droz et al. 1990, Santini et al. 2002, Spano et al. 2012). The majority of patients received the treatment as first line therapy (96.5\% between 17 and 100\%), with an average of five cycles received (1-20) as shown in Table 1.

The risk of bias in the RCT (Shimaoka et al. 1985) was high in relation to the absence of blinding (not only of patients and professionals but also of investigating staff) and the allocation concealment (Fig. 2). For the study of series of cases, the main identified risks of biases were selection and information biases, as a consequence of the investigation's objective lacking a clear description, the inconsecutive inclusion of patients to the study or the absence of comparability between them. The median of follow up was only valuable in one of them, Hoskin \& Harmer (1987), because the rest of the studies did not give precise information on that subject or we did not consider it to be adequate (Fig. 3).

\section{Characteristics of the populations included in the studies}

Characteristics of the control populations analysed in the included studies are displayed in Table 2. All patients had a confirmed diagnosis of thyroid cancer, with different histology and different differentiation grades (51\% were well-differentiated non-medullary carcinomas), in metastatic state and resistant to radioactive iodine treatment. One study provided information about the time lapse between the initial diagnosis of the disease and the first chemotherapy treatment, which was 26 months (2-240 months) (Droz et al. 1990). Another study estimated the time between the initial diagnosis of the disease and the metastatic disease as 9.8 years (1-18 years) (Hussein et al. 2013), and the time between the diagnosis of the metastatic disease and the beginning of the chemotherapy as 21.5 months (12-216 months). Seven studies did not

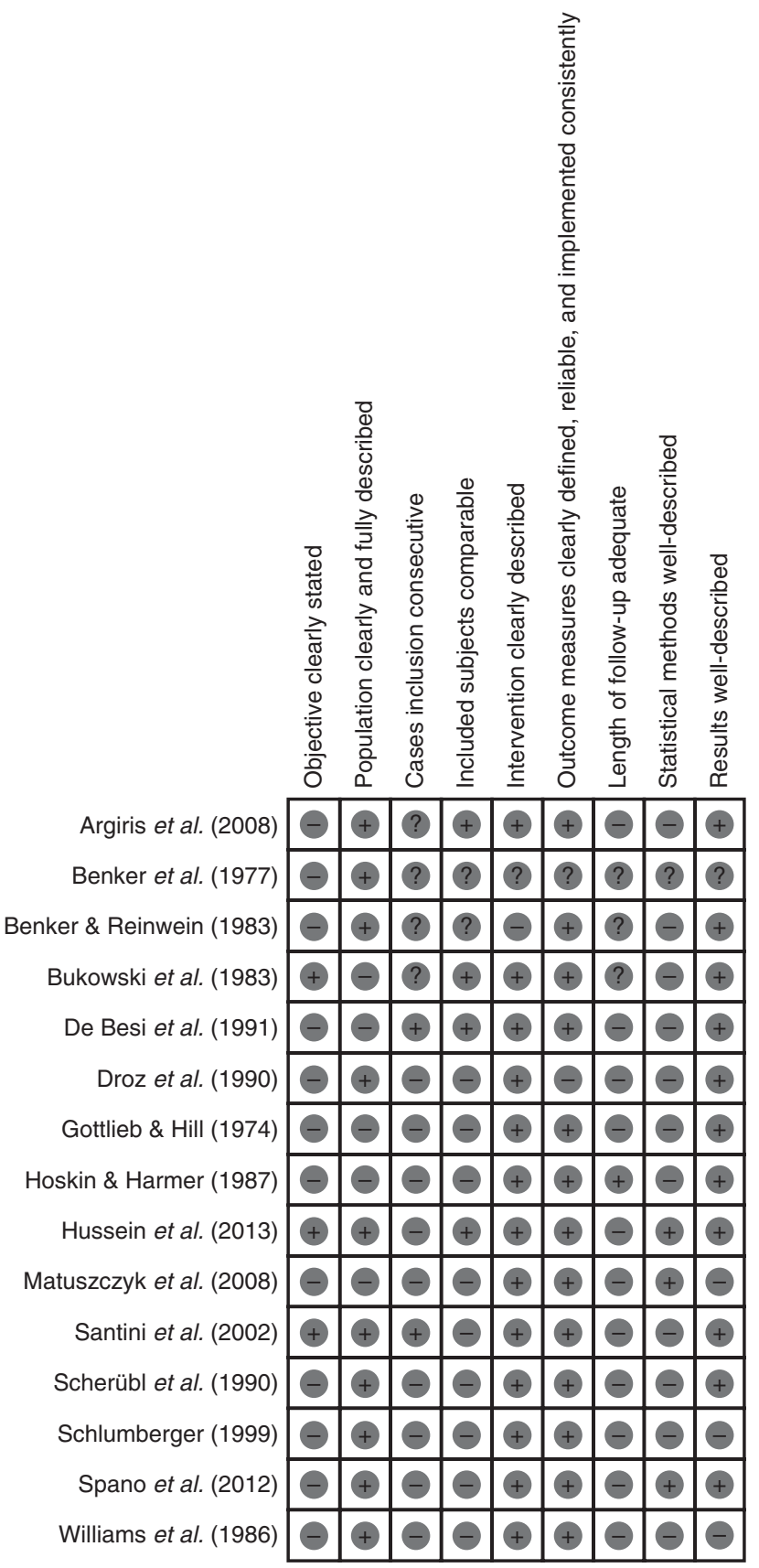

Figure 3

Summary of risks of bias in the included case series.

Published by Bioscientifica Ltd 
Table 2 Features of the reference population analysed. The studies of Williams et al. (1986) and Scherübl et al. (1990) only describe the histology of evaluable patients. The studies of Droz et al. (1990) and Schlumberger \& Parmentier (1989) do not describe the histological subtype (papillary/follicular)

\begin{tabular}{l} 
Study \\
\hline Patients included \\
Evaluable patients \\
Mean Age (years) (rank) \\
Sex (Male/Female), $n$ \\
Differentiated histology, $n$ \\
Papillary histology, $n$ \\
Follicular histology, $n$ \\
Hürtlhe histology, $n$ \\
Mixed histology, $n$ \\
Medullar histology, $n$ \\
Anaplastic histology, $n$ \\
Unknown histology, $n$ \\
PS0-PS1/Karnowski $80-100$ \\
PS2-0S3/Karnowski 40-70
\end{tabular}

\begin{tabular}{|c|c|}
\hline RCT & $\begin{array}{c}\text { Monotherapy } \\
\text { with ADM ó } \\
\text { CDDP }\end{array}$ \\
\hline 84 & 93 \\
\hline 82 & 87 \\
\hline $60(31-87)$ & $51.5(14-76)$ \\
\hline $35 / 49$ & $43 / 47$ \\
\hline 35 & 48 \\
\hline NS & 9 \\
\hline NS & 18 \\
\hline NS & 5 \\
\hline NS & NS \\
\hline 10 & 35 \\
\hline 39 & 9 \\
\hline 0 & 1 \\
\hline NS & 28 \\
\hline NS & 13 \\
\hline
\end{tabular}

\begin{tabular}{c}
\hline \\
Combinations \\
ADM + CDDP \\
\hline 97 \\
88 \\
$57(22-87)$ \\
$42 / 47$ \\
47 \\
21 \\
19 \\
1 \\
2 \\
28 \\
12 \\
2 \\
39 \\
27
\end{tabular}

\begin{tabular}{c}
$\begin{array}{c}\text { Combinations } \\
\text { ADM without } \\
\text { CDDP }\end{array}$ \\
\hline 113 \\
103 \\
$60(32-89)$ \\
$21 / 40$ \\
57 \\
15 \\
31 \\
3 \\
0 \\
17 \\
38 \\
1 \\
36 \\
10 \\
\hline
\end{tabular}

\begin{tabular}{c}
\hline $\begin{array}{c}\text { Others } \\
\text { treatments }\end{array}$ \\
\hline 86 \\
84 \\
$56(19-84)$ \\
$45 / 41$ \\
55 \\
24 \\
14 \\
2 \\
0 \\
20 \\
11 \\
0 \\
20 \\
23 \\
\hline
\end{tabular}

\begin{tabular}{c}
\hline Total \\
\hline 473 \\
444 \\
$56.9(14-89)^{a}$ \\
$186 / 224^{b}$ \\
$242(51 \%$ of total) \\
69 \\
83 \\
11 \\
7 \\
$110(23 \%$ of total $)$ \\
$109(23 \%$ of total) \\
$4(0.8 \%$ of total $)$ \\
$123(63 \%)$ \\
$73(37 \%)$
\end{tabular}

RCT, randomized clinical trial; ADM, Adriamycin; CDDP, cisplatin; PS, performance status; NS, not specified.

aData for global series from Droz et al. (1990) (52 patients).

${ }^{b}$ The studies of Williams et al. (1986), Scherübl et al. (1990) and Matuszczyk et al. (2008) gave information about evaluable patients (410 of 473 patients).

provide data about performance status (PS) of the patients (Gottlieb \& Hill 1974, Benker et al. 1977, Benker \& Reinwein 1983, Bukowski et al. 1983, Santini et al. 2002, Matuszczyk et al. 2008, Hoskin \& Harmer 1987). Six studies measured the initial PS using the Eastern Cooperative Oncology Group (ECOG) system (Shimaoka et al. 1985, Schlumberger \& Parmentier 1989, Droz et al. 1990, Argiris et al. 2008, Spano et al. 2012, Hussein et al. 2013) and three using the Karnowski system (Williams et al. 1986, Scherübl et al. 1990, De Besi et al. 1991). In six studies, the inclusion in the study with PS 0-3/Karnowski 40-100 was allowed, with nearly $40 \%$ of patients with $P S \geq 2$
(Shimaoka et al. 1985, Williams et al. 1986, Schlumberger \& Parmentier 1989, Droz et al. 1990, Spano et al. 2012, Hussein et al. 2013).

\section{Response to treatment and clinical benefit}

Classification systems and techniques used for the response assessment in the diverse studies are described in Table 3 (Miller et al. 1981, Young et al. 1999, Eisenhauer et al. 2009). The first response assessment was made after 8-9 weeks in five studies (Gottlieb \& Hill 1974, Droz et al. 1990, Scherübl et al. 1990, Spano et al. 2012,

Table 3 Systems of classification and evaluation of response methods

\begin{tabular}{|c|c|}
\hline Rating system response & References \\
\hline OMS & $\begin{array}{l}\text { Gottlieb \& Hill (1974), Benker et al. (1977), Benker \& Reinwein (1983), Bukowski et al. (1983), } \\
\text { Shimaoka et al. (1985), Williams et al. (1986), Hoskin \& Harmer (1987), Schlumberger \& } \\
\text { Parmentier (1989), Scherübl et al. (1990), Droz et al. (1990), De Besi et al. (1991), Santini et al. } \\
\text { (2002), Argiris et al. (2008) }\end{array}$ \\
\hline RECIST & Spano et al. (2012) \\
\hline EORTC-99 & Matuszczyk et al. (2008) \\
\hline NE & Hussein et al. (2013) \\
\hline \multicolumn{2}{|l|}{ Valuation technique response } \\
\hline Chest x-ray + bone scan & $\begin{array}{l}\text { Gottlieb \& Hill (1974), Bukowski et al. (1983), Shimaoka et al. (1985), Schlumberger \& Parmentier } \\
\text { (1989) }\end{array}$ \\
\hline Furthermore, echography & Hoskin \& Harmer (1987), Droz et al. (1990), De Besi et al. (1991) \\
\hline $\mathrm{CT}$ & Santini et al. (2002), Argiris et al. (2008), Spano et al. (2012), Hussein et al. (2013) \\
\hline MRI & Argiris et al. (2008) \\
\hline PET & Matuszczyk et al. (2008) \\
\hline
\end{tabular}

CT, computed tomography; MRI, magnetic resonance imaging; PET, positron emission tomography; NE, not specified. 
Hussein et al. 2013), in three assessment was performed at between 3 and 4 weeks (Bukowski et al. 1983, Shimaoka et al. 1985, Hoskin \& Harmer 1987) and it was performed much later (among 12 and 49 months) in another three studies (Santini et al. 2002, Argiris et al. 2008, Matuszczyk et al. 2008). Five studies did not report this data (Benker et al. 1977, Benker \& Reinwein 1983, Williams et al. 1986, Schlumberger \& Parmentier 1989, De Besi et al. 1991). Four included information about the time to response in 3 months (three studies) and 9 months (Gottlieb \& Hill 1974, Bukowski et al. 1983, Droz et al. 1990, De Besi et al. 1991). The rest of the studies did not provide information on that variable. Considering the studies globally, the RR was $22.2 \%$ (0-57\%), with $20 \%$ PR and $2.5 \%$ CR, with an estimate of $27.1 \%(2.8 \% \mathrm{CR})$ in the four studies which just included patients with advanced CDT-RTI (Tables 4 and 5) (Santini et al. 2002, Matuszczyk et al. 2008, Spano et al. 2012, Hussein et al. 2013). It was possible to obtain data for assessed histology and response for 13 studies with a total of 179 cases. The RR was 25\%, with $3.4 \%$ of CR. Eight studies reported detailed response data by histologic subtype (97 patients) (Benker et al. 1977, Benker \& Reinwein 1983, Bukowski et al. 1983, Scherübl et al. 1990, De Besi et al. 1991, Santini et al. 2002, Matuszczyk et al. 2008, Spano et al. 2012). In 39 cases, there were papillary tumours (RR 25.6\%, CR 2.5\%). There were 58 patients with follicular tumours (RR 32.75\%, CR 5.1\%) as shown in Tables 6 and 7.

The clinical benefit (CB) for the global results of studies (405 patients) was $54.3 \%(25-93 \%)$ and in the studies which were limited to patients with DTC-RTI, 61.4\% (Tables 5 and 7). In 129 patients with DTC-RTI (for which individual data were available), the CB was $64.34 \%$, $81.1 \%$ and $65.45 \%$ in total, papillary and follicular groups respectively (Tables 8 and 9) The mean length of response varied between 3 and 14 months, showing long-lasting CR $(60+$ months). Seven out of 16 studies estimated the median duration (Gottlieb \& Hill 1974, Shimaoka et al. 1985, Williams et al. 1986, Droz et al. 1990, De Besi et al. 1991, Spano et al. 2012, Hussein et al. 2013) with estimates ranging between 3 (Droz et al. 1990) and 15.6 months (Spano et al. 2012). In three studies, the data about the duration of the response to the chemotherapeutic treatments were stratified based on its quality, noting the long duration of the CR in these studies (between 2.3 and 41.3 months, $30.2+/ 60+$ months) (Bukowski et al. 1983, Shimaoka et al. 1985, Argiris et al. 2008).

\section{PFS and global survival}

Three studies analysed the PFS reporting times of 6 months (3-12), 10 months (1.6-22) and 6 months (4.9-7) respectively (Argiris et al. 2008, Spano et al. 2012, Hussein et al. 2013). One study, Argiris et al. (2008) expressed the survival as the probability, whereas the rest of the included studies expressed it statistically, this complicated comparisons between data. Five studies collected individual survival data and patients status, and from these survival probability could be calculated (Bukowski et al. 1983, Hoskin \& Harmer 1987, Schlumberger \& Parmentier 1989,

Table 4 Response rate to chemotherapy according to the therapeutic scheme

\begin{tabular}{|c|c|c|c|c|c|}
\hline Study & $n$ & NA $(n) \%$ & CR (n) \% & PR (n) \% & CR + PR (n) RR \\
\hline $\mathrm{RCT}$ & 84 & $\begin{array}{c}2 \\
2.3 \%\end{array}$ & $\begin{array}{c}5 \\
5.9 \%\end{array}$ & $\begin{array}{c}13 \\
15.4 \%\end{array}$ & $\begin{array}{c}18 \\
21 \%\end{array}$ \\
\hline Monotherapy ADM or cisplatin & 93 & $\begin{array}{c}6 \\
6.4 \% \\
(0-13.6 \%)\end{array}$ & $\begin{array}{c}0 \\
0 \%\end{array}$ & $\begin{array}{c}14 \\
15 \% \\
(0-37 \%)\end{array}$ & $\begin{array}{c}14 \\
15 \% \\
(0-37 \%)\end{array}$ \\
\hline ADM + cisplatin & 97 & $\begin{array}{c}7 \\
7.2 \% \\
(0-21.4 \%)\end{array}$ & $\begin{array}{c}2 \\
2 \% \\
(0-9.5 \%)\end{array}$ & $\begin{array}{c}14 \\
14.4 \% \\
(0-33 \%)\end{array}$ & $\begin{array}{c}16 \\
16.4 \% \\
(0-42.8 \%)\end{array}$ \\
\hline ADM without cisplatin & 113 & $\begin{array}{c}10 \\
8.8 \% \\
(0-14.2 \%)\end{array}$ & $\begin{array}{c}3 \\
2.6 \% \\
(0-9.5 \%)\end{array}$ & $\begin{array}{c}25 \\
22.1 \% \\
(0-30.7 \%)\end{array}$ & $\begin{array}{c}28 \\
24.7 \% \\
(0-36.3 \%)\end{array}$ \\
\hline Others & 86 & $\begin{array}{c}2 \\
2.3 \% \\
(0-2.3 \%)\end{array}$ & $\begin{array}{c}2 \\
2.3 \% \\
(0-7 \%)\end{array}$ & $\begin{array}{c}27 \\
31.3 \% \\
(0-50 \%)\end{array}$ & $\begin{array}{c}29 \\
33.7 \% \\
(6-57 \%)\end{array}$ \\
\hline Total & 473 & $\begin{array}{c}27 \\
5.7 \% \\
(0-21.4 \%)\end{array}$ & $\begin{array}{c}12 \\
2.5 \\
(0-9.5 \%)\end{array}$ & $\begin{array}{c}93 \\
19.6 \% \\
(0-50 \%)\end{array}$ & $\begin{array}{c}105 \\
22.19 \% \\
(0-57 \%)\end{array}$ \\
\hline
\end{tabular}

NA, not assessable; $C R$, complete response; $P R$, partial response; $R R$, response rate $=C R+P R /$ total number of patients; $R C T$, randomized clinical trial; $A D M$, adriamycin; rank of outcomes in individual studies of each group. 
Table 5 Studies that include only DTC-RTI

\begin{tabular}{|c|c|c|c|c|c|}
\hline Study, year & $\begin{array}{l}\text { Santini } \\
\text { et al. (2002) }\end{array}$ & $\begin{array}{l}\text { Matuszczyk } \\
\text { et al. (2008) }\end{array}$ & $\begin{array}{l}\text { Spano et al. } \\
(2012)\end{array}$ & $\begin{array}{l}\text { Hussein et al. } \\
(2013)\end{array}$ & Total \\
\hline \multicolumn{6}{|l|}{ Patients characteristics } \\
\hline Total number of patients & 14 & 22 & 14 & 20 & 70 \\
\hline Number of evaluable patients & 14 & 19 & 14 & 20 & 67 \\
\hline Mean age, years (rank) & $57(39-64)$ & $61(22-77)$ & $\begin{array}{l}63 \text { (median) } \\
(31-85)\end{array}$ & $65(54-80)$ & $61.5(22-85 \%)$ \\
\hline Sex (male/female) $n(\%)$ & $7 / 7(50 / 50)$ & $8 / 11(35 / 50)$ & $8 / 6(57-43)$ & $8 / 12(40 / 60)$ & $\begin{array}{l}31 / 36 \\
(46.3 / 53.7 \%)\end{array}$ \\
\hline Differentiated histology, $n(\%)$ & $14(100 \%)$ & $22(100 \%)$ & $14(100 \%)$ & $20(100 \%)$ & $70(100 \%)$ \\
\hline Papillary histology, $n(\%)$ & $6(21.4 \%)$ & $7(32 \%)$ & $8(57 \%)$ & $15(75 \%)$ & $36(51.4 \%)$ \\
\hline Follicular histology, $n(\%)$ & $6(21.4 \%)$ & $15(68 \%)$ & $6(43 \%)$ & $5(25 \%)$ & $32(45.7 \%)$ \\
\hline Hürtle histology, $n(\%)$ & $2(14.2 \%)$ & $0(0 \%)$ & $0(0 \%)$ & $0(0 \%)$ & $2(2.8 \%)$ \\
\hline Mixed histology, $n(\%)$ & $0(0 \%)$ & $0(0 \%)$ & $0(0 \%)$ & $0(0 \%)$ & $0(0 \%)$ \\
\hline Performance Status/Grading System & NS & NS & ECOG $0-3$ & ECOG 1-3 & - \\
\hline PS0-PS1 & NS & NS & $7(50 \%)$ & NS & - \\
\hline PS2-PS3 & NS & NS & $7(50 \%)$ & $\begin{array}{l}\text { NS (PS1-2:16 (80\%) } \\
\text { PS3: } 4(20 \%))\end{array}$ & - \\
\hline \multicolumn{6}{|l|}{ Assessment of response } \\
\hline Treatment schedule & $\begin{array}{l}\text { Carboplatin- } \\
\text { 4epiADM }\end{array}$ & ADMs./ADMts & GEMOX & $\begin{array}{c}\mathrm{ADM}+\mathrm{CDDP} / \mathrm{CLF}+ \\
\mathrm{ADM}+\mathrm{CDDP}\end{array}$ & - \\
\hline Classification system response & OMS & EORTC-99 & RECIST & NS & - \\
\hline CR $+P R, n$, (RR by study) & 6 & 1 & 8 & 4 & 19 \\
\hline $\mathrm{RR}$ & $43 \%$ & $(4.5 \%)$ & $57 \%$ & $(20 \%)$ & $(27.1 \%)$ \\
\hline Clinical benefit (CB) & $\begin{array}{l}13 \\
93 \%\end{array}$ & $\begin{array}{l}8 \\
(36.3 \%)\end{array}$ & $\begin{array}{l}12 \\
86 \%\end{array}$ & $\begin{array}{l}10 \\
(50 \%)\end{array}$ & $\begin{array}{l}43 \\
(61.4 \%)\end{array}$ \\
\hline CR, $n$ (\% by study) & 1 & 0 & 1 & 0 & 2 \\
\hline$\%$ Total & (7) & (0) & (7) & (0) & $(2.8 \%)$ \\
\hline $\begin{array}{l}\text { PR, } n \text { ( } \% \text { by study) } \\
\% \text { Total }\end{array}$ & $\begin{array}{l}5 \\
(36)\end{array}$ & $\begin{array}{l}1 \\
(4.5)\end{array}$ & $\begin{array}{l}7 \\
(50)\end{array}$ & $\begin{array}{l}4 \\
(20)\end{array}$ & $\begin{array}{l}17 \\
(24.2 \%)\end{array}$ \\
\hline $\begin{array}{l}\text { SD, } n \text { (\% by study) } \\
\% \text { Total }\end{array}$ & $\begin{array}{l}7 \\
(50)\end{array}$ & $\begin{array}{l}7 \\
(31.8)\end{array}$ & $\begin{array}{l}4 \\
(29)\end{array}$ & $\begin{array}{l}6 \\
(30)\end{array}$ & $\begin{array}{l}24 \\
(34.2 \%)\end{array}$ \\
\hline PD, $n$ (\% by study) & 1 & 11 & 2 & 10 & 24 \\
\hline$\%$ Total & (7) & $(50)$ & $(14)$ & $(50)$ & $(34.2 \%)$ \\
\hline NA, $n$ ( $\%$ by study) & $\begin{array}{l}0 \\
(0 \%)\end{array}$ & $\begin{array}{l}3 \\
(13.6 \%)\end{array}$ & $\begin{array}{l}0 \\
(0 \%)\end{array}$ & $\begin{array}{l}0 \\
(0 \%)\end{array}$ & $\begin{array}{l}3 \\
(4.2 \%)\end{array}$ \\
\hline
\end{tabular}

CDT-RAl, differentiated non-medullary refractory radioactive iodine thyroid cancer; PS, performance status; NS, unspecified; ADM, adriamycin; CDDP, cisplatin; GEMOX, gemcitabine + oxaliplatin; CLF, cyclophosphamide; CR, complete response; PR, partial response; RR, response rate=CR+PR/total number of patients; SD, stable disease; $C B$, clinical benefit $=C R+P R+S D /$ total number of patients; $P D$, progression disease; NA, not assessable.

Santini et al. 2002, Spano et al. 2012) (Table 10). In addition, the probability of survival of all individuals with CDT-RTI (54 patients) was calculated. Median survival was estimated at 18 months (95\% CI 0-37.5) and univariate survival analysis was performed in relation to age $(>/<45$ years), sex $(\mathrm{M} / \mathrm{F})$, histological type (papillary/follicular), number of metastases $(1$ or $2 />2$ ), metastatic site, monochemotherapy scheme versus combination chemotherapy and if the treatment was established before or after the year 2000. We found a statistically significant difference in favour of combination chemotherapy versus monotherapy (15.2 versus 35.6 months; $P=0.001$ ) (Fig. 4) and in those which were treated after the year 2000 compared with those treated previously (41.2 versus 13 months, $P=0.000$ ). In multivariate analysis, the date of patients' treatment (before or after 2000) was the only independent variable in relation to survival. In another three studies, there were observed differences in the median survival between responders to the treatment (from $11+$ to 36 months) and nonresponders (between 4 and 19 months) studies (Gottlieb \& Hill 1974, Santini et al. 2002, Argiris et al. 2008). Two studies expressed these differences as the average, in 15.5 versus 3 months and 19 versus 5.4 months respectively (Benker \& Reinwein 1983, Hoskin \& Harmer 1987).

\section{Discussion}

In 2012, the estimated incidence of thyroid cancer in Spain was 2059 cases (3.4/100 000), with a mortality of 286 cases (0.3/100 000) (Ferlay et al. 2015). Among them, welldifferentiated thyroid cancer is the most frequent and it

Published by Bioscientifica Ltd. 
Table 6 Response rate: individual response data in CDT-RTI

\begin{tabular}{l} 
Study, year \\
\hline Monotherapy \\
Gottlieb \& Hill (1974) \\
Schlumberger \& Parmentier (1989) \\
Matuszczyk et al. (2008) \\
Combination therapy \\
Benker et al. (1977) \\
Benker \& Reinwein (1983) \\
Bukowski et al. (1983) \\
Shimaoka et al. (1985) \\
Williams et al. (1986) \\
De Besi et al. (1991) \\
Scherübl et al. (1990) \\
Santini et al. (2002) \\
Argiris et al. (2008) \\
Spano et al. (2012) \\
Total \\
\end{tabular}

\begin{tabular}{c}
$\begin{array}{c}\text { No. patients } \\
\text { with DTC } \\
\text { (\% overall study) }\end{array}$ \\
\hline \\
$15(50 \%)$ \\
$7(41 \%)$ \\
$19(100 \%)$ \\
$8(38 \%)$ \\
$21(50 \%)$ \\
$5(45 \%)$ \\
$35(42 \%)$ \\
$7(32 \%)$ \\
$8(36 \%)$ \\
$8(40 \%)$ \\
$14(100 \%)$ \\
$15(88 \%)$ \\
$14(100 \%)$ \\
$176(100 \%)$ \\
\end{tabular}

\begin{tabular}{c} 
\\
NA (n) \\
\hline \\
0 \\
0 \\
0 \\
1 \\
2 \\
0 \\
0 \\
0 \\
0 \\
2 \\
0 \\
0 \\
0 \\
$\mathbf{5}$ \\
$(\mathbf{2 . 8} \%)$ \\
\end{tabular}

\begin{tabular}{ccc}
\hline & & \\
CR $(\boldsymbol{n})$ & & PR (n) \\
\cline { 1 - 1 } 0 & & 5 \\
0 & & 0 \\
0 & & 1 \\
& & \\
2 & & 1 \\
0 & & 7 \\
0 & & 1 \\
2 & & 6 \\
0 & & 1 \\
0 & & 3 \\
0 & & 0 \\
1 & & 5 \\
0 & & 1 \\
1 & & 7 \\
6 & & 38 \\
$(3.4 \%)$ & $(21.6 \%)$ \\
\hline
\end{tabular}

\begin{tabular}{|c|c|}
\hline $\mathrm{CR}+\mathrm{PR}(n)$ & $\mathbf{S D}+\mathbf{P D}(n)$ \\
\hline 5 & 10 \\
\hline 0 & 7 \\
\hline 1 & 18 \\
\hline 3 & 4 \\
\hline 7 & 12 \\
\hline 1 & 4 \\
\hline 8 & 27 \\
\hline 1 & 6 \\
\hline 3 & 5 \\
\hline 0 & 6 \\
\hline 6 & 8 \\
\hline 1 & 14 \\
\hline 8 & 6 \\
\hline 44 & 127 \\
\hline$(25 \%)$ & (72.15\%) \\
\hline
\end{tabular}

$C R$, complete response; $P R$, partial response; $R R$, response rate $=C R+P R /$ total number of patients; $S D$, stable disease; $P D$, progressive disease; $N A$, not assessable.

does not usually compromise the survival of patients who suffer from it, except for a small proportion that will become resistant to radioactive iodine treatment (Durante et al. 2006). The low casuistic could be one of the reasons why the research on chemotherapy of this condition has been scarce. Just 16 series of patients have been identified in 40 years; these series also had a high bias risk and did not achieve a total of 250 patients with well-differentiated tumours. Notwithstanding, in the current literature, there is no doubt in accepting as something sufficiently investigated, that chemotherapy has little function in the treatment of these patients.

Studies published in the 1970s, 80s, and 90s included all types of histology (well-differentiated tumours, in proportions between 15 and 50\%, medullary and anaplastic) (Gottlieb \& Hill 1974, Bukowski et al. 1983, Shimaoka et al. 1985, Williams et al. 1986, Hoskin \& Harmer 1987, De Besi et al. 1991). Anaplastic ones were excluded in the 1990s (Schlumberger \& Parmentier 1989, Droz et al. 1990, Scherübl et al. 1990). From 2002 onward, four small studies were published, which only selected patients with well-differentiated tumours (Santini et al. 2002, Matuszczyk et al. 2008, Spano et al. 2012, Hussein et al. 2013). Therefore, it seems difficult to draw conclusions applicable to our current knowledge of series prior to the 2000s, given the differences that are already known in the behaviour of thyroid neoplasms and depending on the histology. Considering the data of these last studies seems insufficient.

Heterogeneity in selection adds to the diversity of received treatment and response assessment techniques, which have varied through the decades. In the 1970s,

Table 7 Response rate: individual response data relative to histological subtype ${ }^{a}$

\begin{tabular}{lcc}
\hline Total data & & Patients $(\boldsymbol{n}) \%$ \\
\cline { 1 - 1 } DTC-RTI & 176 \\
Papillary type & $100 \%$ \\
Follicular type & 39 \\
& $100 \%$ \\
& 58 \\
\hline
\end{tabular}

\begin{tabular}{c}
\hline NA $(\boldsymbol{n}) \%$ \\
\hline 5 \\
$2.84 \%$ \\
1 \\
$2.56 \%$ \\
2 \\
$3.44 \%$ \\
\hline
\end{tabular}

\begin{tabular}{c}
\hline $\mathbf{C R}(\boldsymbol{n}) \%$ \\
\hline 6 \\
$3.4 \%$ \\
1 \\
$2.56 \%$ \\
3 \\
$5.1 \%$ \\
\hline
\end{tabular}

\begin{tabular}{c}
\hline PR $(\boldsymbol{n}) \%$ \\
\hline 38 \\
$21.59 \%$ \\
9 \\
$23.07 \%$ \\
16 \\
$27.58 \%$ \\
\hline
\end{tabular}

\begin{tabular}{c}
\hline $\mathbf{C R}+\mathbf{P R}(\boldsymbol{n}) \mathbf{R R}$ \\
\hline 44 \\
$25 \%$ \\
10 \\
$25.64 \%$ \\
19 \\
$32.75 \%$ \\
\hline
\end{tabular}

\begin{tabular}{c}
\hline SD + PD (n) \% \\
\hline 127 \\
$72.15 \%$ \\
28 \\
$71.79 \%$ \\
37 \\
$63.79 \%$
\end{tabular}

CDT-RTI, differentiated non-medullary refractory radioactive iodine thyroid cancer; NA, not assessable; CR, complete response; PR, partial response; $R R$, response rate $=C R+P R /$ total number of patients; $S D$, stable disease; $P D$, progressive disease an seven patients the papillary or follicular histological subtype is not reported. 
Table 8 Clinical benefit of chemotherapy according to the therapeutic scheme

\begin{tabular}{|c|c|c|c|c|c|c|}
\hline Study & n & NA $(n) \%$ & $\begin{array}{c}\mathbf{C R}+\mathbf{P R}(\boldsymbol{n}) \mathbf{R R} \\
(\%)\end{array}$ & SD (n) \% & CB (n) \% & PD (n) \% \\
\hline \multirow[t]{2}{*}{$\mathrm{RCT}$} & 84 & 2 & 18 & 22 & 40 & 42 \\
\hline & & $2.3 \%$ & $21.4 \%$ & $26.1 \%$ & $48.7 \%$ & $50 \%$ \\
\hline \multirow[t]{2}{*}{ Monotherapy, ADM or CDDP } & 93 & 6 & 14 & 26 & 40 & 47 \\
\hline & & $\begin{array}{c}6.4 \% \\
(0-13.6 \%)\end{array}$ & $\begin{array}{c}15 \% \\
(0-37 \%)\end{array}$ & $\begin{array}{c}27.9 \% \\
(23-32 \%)\end{array}$ & $\begin{array}{c}43 \% \\
(32-63.3)\end{array}$ & $\begin{array}{c}51 \% \\
(37-64)\end{array}$ \\
\hline \multirow[t]{2}{*}{ ADM + cisplatin } & 69 & 1 & 14 & 31 & 45 & 23 \\
\hline & & $\begin{array}{c}1.4 \% \\
(0-4.5 \%)\end{array}$ & $\begin{array}{c}20.2 \% \\
(0-42.8 \%)\end{array}$ & $\begin{array}{c}44.9 \% \\
(24-55 \%)\end{array}$ & $\begin{array}{c}65.2 \% \\
(50-81 \%)\end{array}$ & $\begin{array}{l}33.3 \% \\
(25-50)\end{array}$ \\
\hline \multirow[t]{2}{*}{ ADM without cisplatin } & 102 & 10 & 24 & 36 & 60 & 32 \\
\hline & & $\begin{array}{c}9.8 \% \\
(0-14.2 \%)\end{array}$ & $\begin{array}{c}23.5 \% \\
(0-36.3 \%)\end{array}$ & $\begin{array}{c}35.2 \% \\
(8-59 \%)\end{array}$ & $\begin{array}{l}58.8 \% \\
(25-67)\end{array}$ & $\begin{array}{l}31.3 \% \\
(19-67)\end{array}$ \\
\hline \multirow[t]{3}{*}{ Others } & 57 & 2 & 15 & 20 & 35 & 20 \\
\hline & & $3.5 \%$ & $26.3 \%$ & $35 \%$ & $61.4 \%$ & $35 \%$ \\
\hline & & $(0-16.6 \%)$ & $(6-57 \%)$ & $(17-50 \%)$ & $(25-93 \%)$ & $(7-58 \%)$ \\
\hline \multirow[t]{3}{*}{ Total } & 405 & 21 & 85 & 135 & 220 & 164 \\
\hline & & $5.1 \%$ & $20.9 \%$ & $33.3 \%$ & $54.3 \%$ & $40.4 \%$ \\
\hline & & $(0-14.2 \%)$ & $(0-57 \%)$ & $(8-59 \%)$ & $(25-93 \%)$ & \\
\hline
\end{tabular}

NA, not assessable; $C R$, complete response; $P R$, partial response; $R R$, response rate $=C R+P R /$ total number of patients; $S D$, stable disease; $C B$, clinical benefit $=C R+P R+S D /$ total number of patients; $P D$, progressive disease; $R C T$, randomized clinical trial; $A D M$, adriamycin. For analysis of the CB three studies (Bukowski et al. (1983), Williams et al. (1986), Hoskin \& Harmer (1987)) were excluded as not providing data on SD and PD (rank of individual study results).

those most studied were adriamycin administered singly or in combination without cisplatin and in any type of histology. Studies with cisplatin-adriamycin combination have been published since 1985 (Williams et al. 1986, Scherübl et al. 1990, De Besi et al. 1991, Hussein et al. 2013), and in the twenty-first century, already three studies have assessed treatment with more modern drugs and techniques (Santini et al. 2002, Argiris et al. 2008, Spano et al. 2012). In recent years and in well differentiated non-medullary tumours, series have been published with few patients assessing the efficacy of adriamycin (Matuszczyk et al. 2008), adriamycin combined with cisplatin (Hussein et al. 2013), GEMOX (Spano et al. 2012) epiadriamycin combined with carboplatin (Santini et al. 2002) in conditions of hypothyroidism and the combination of adriamycin with alpha interferon
(Argiris et al. 2008) with very different results (RR between 6 and 50\%). None of the studies that assessed monotherapy achieved $\mathrm{CR}$, whose rate was 3.2\% (2-6\%) for treatments with combinations. Although limited, the possibility of obtaining CR seems important, due to the fact that they have been described as long-lasting and with a probable relationship to the survival (Bukowski et al. 1983, Shimaoka et al. 1985, Argiris et al. 2008). Currently, a relation between PS and chemotherapy response is recognised, although the inclusion in clinical trials of patients with PS $>2$ is rare. In this series, nearly $40 \%$ of the patients presented a PS $\geq 2$, a very high proportion in comparison to those published in the DECISION study (3.4\%) (Brose et al. 2014). Therefore, better results could be for the treatment with chemotherapy in patients with better PS. Although there does seem to be sufficient

Table 9 Clinical benefit to chemotherapy according to histological subtype ${ }^{a}$

\begin{tabular}{|c|c|c|c|c|c|c|c|c|}
\hline DTC-RTI & $\begin{array}{l}\text { Patients } \\
\text { (n) } \%\end{array}$ & NA (n) \% & CR (n) \% & PR (n) \% & CR + PR (n) RR & SD (n) \% & $\begin{array}{c}C R+P R+S D \\
\text { (n) } C B\end{array}$ & PD (n) \% \\
\hline \multirow[t]{2}{*}{ Total group } & 129 & 5 & 4 & 30 & 34 & 49 & 83 & 41 \\
\hline & $100 \%$ & $1.61 \%$ & $3.1 \%$ & $23.25 \%$ & $26.35 \%$ & $37.98 \%$ & $64.34 \%$ & $31.78 \%$ \\
\hline \multirow[t]{2}{*}{ Papillary type } & 37 & 1 & 1 & 9 & 10 & 20 & 30 & 6 \\
\hline & $100 \%$ & $2.7 \%$ & $2.7 \%$ & $24.32 \%$ & $27.02 \%$ & $54.05 \%$ & $81.08 \%$ & $16.21 \%$ \\
\hline \multirow[t]{2}{*}{ Folicular type } & 55 & 2 & 3 & 15 & 18 & 18 & 36 & 17 \\
\hline & $100 \%$ & $3.63 \%$ & $5.45 \%$ & $27.27 \%$ & $32.72 \%$ & $32.72 \%$ & $65.45 \%$ & $30.9 \%$ \\
\hline
\end{tabular}

CDT-RTI, differentiated non-medullary refractory radioactive iodine thyroid cancer; NA, not assessable; CR, complete response; PR, partial response; RR, response rate $=C R+P R /$ total number of patients; SD, stable disease; PD, progression disease.

an seven patients the papillary or follicular histological subtype was not reported.

http://erc.endocrinology-journals.org DOI: $10.1530 /$ ERC-15-0194
(C) 2016 Society for Endocrinology Printed in Great Britain
Published by Bioscientifica Ltd 
Table 10 Overall survival

\begin{tabular}{|c|c|c|c|}
\hline Study & $n$ & $\begin{array}{l}\text { Median survival } \\
\text { (months) }\end{array}$ & $\begin{array}{l}\text { Mean survival } \\
\text { (months) }\end{array}$ \\
\hline Gottlieb \& Hill (1974) & 30 & NS & NS \\
\hline $\begin{array}{l}\text { Benker \& Reinwein } \\
\quad(1983)\end{array}$ & 52 & NS & $9^{a}$ \\
\hline \multirow[t]{3}{*}{ Bukowski et al. (1983) } & 11 & 4 & 9 \\
\hline & & $95 \% \mathrm{Cl}(2.4-5.5)$ & $95 \% \mathrm{Cl}(0-18.5)$ \\
\hline & & Rank $(2-60+)$ & Rank $(2-60+)$ \\
\hline Williams et al. (1986) & 28 & NS & $11.7^{a}$ \\
\hline \multirow{4}{*}{$\begin{array}{l}\text { Hoskin \& Harmer } \\
\quad(1987)^{\mathrm{b}}\end{array}$} & 29 & 10 & $11.9^{a}$ \\
\hline & & $95 \% \mathrm{Cl}(3.8-16.1)$ & 14.2 \\
\hline & & Rank (1-54) & $95 \% \mathrm{Cl}(8.3-20)$ \\
\hline & & & Rank (1-54) \\
\hline \multirow[t]{2}{*}{ De Besi et al. (1991) } & 22 & $16^{a}$ & NS \\
\hline & & Rank (2-57) & \\
\hline \multirow{3}{*}{$\begin{array}{l}\text { Schlumberger \& } \\
\text { Parmentier (1989) }\end{array}$} & 17 & 13 & 12.3 \\
\hline & & $95 \% \mathrm{Cl}(11.8-14.1)$ & $95 \% \mathrm{Cl}(0-18.5)$ \\
\hline & & Rank (1-26+) & Rank (1-26+) \\
\hline Droz et al. (1990) & 12 & NS & $12^{a}$ \\
\hline Study A & & & Rank (1-46) \\
\hline Droz et al. (1990) & 22 & NS & $20^{a}$ \\
\hline Study B & & & Rank (3-60) \\
\hline Droz et al. (1990) & 19 & NS & $14^{a}$ \\
\hline Study C & & & Rank (1-56) \\
\hline Droz et al. (1990) & 12 & NS & $14^{a}$ \\
\hline Study D & & & Rank (2-48) \\
\hline Droz et al. (1990) & 7 & NS & $7^{a}$ \\
\hline Study E & & & Rank (4-13) \\
\hline \multirow[t]{2}{*}{ Argiris et al. (2008) } & 17 & 26.4 & NS \\
\hline & & $95 \% \mathrm{Cl}(6.7-46.1)$ & \\
\hline \multirow[t]{3}{*}{ Santini et al. $(2002)^{b}$} & 14 & Not reached & 34.7 \\
\hline & & Rank (9-41) & $95 \% \mathrm{Cl}(27.7-41.8)$ \\
\hline & & & Rank (9-41) \\
\hline \multirow[t]{3}{*}{ Spano et al. $(2012)^{b}$} & 14 & Not reached & 44.3 \\
\hline & & Follow-up: 19.8 & $95 \% \mathrm{Cl}(30.3-58.4)$ \\
\hline & & & Rank $(2-62+)$ \\
\hline \multirow[t]{2}{*}{ Hussein et al. (2013) } & 20 & NS & $9^{a}$ \\
\hline & & & Rank (6-12) \\
\hline
\end{tabular}

NS, not specified.

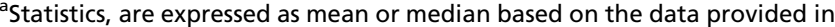
the different studies.

${ }^{\text {bS }}$ urvival probability calculated based on individual survival data and status of patients at follow-up.

evidence of chemotherapy's effectiveness in terms of the RR and the response's quality, it could be even superior to sorafenib. In particular, this should be considered because the significance of the response to chemotherapy in advanced radioactive iodine refractory thyroid carcinoma was never assessed properly, and few studies have been performed with modern methodology and chemotherapy.

Extracting conclusions from the PFS data is also difficult, because they are described scarcely and, generally, as statistics and not as probabilities, thus comparison with actual results is complex (Argiris et al. 2008, Spano et al. 2012, Hussein et al. 2013). Just one small study, Spano et al. (2012) provided individual data for the PFS and the progression status at the end of the monitoring, the median PFS was 10 months with 95\% CI of 4.1-16.2, similar to the one achieved with sorafenib (Brose et al. 2014). As for the chemotherapy effect on the survival, data is insufficient and, due to the variable course of these tumours, with patients who stay several years with disseminated disease, the evaluation of
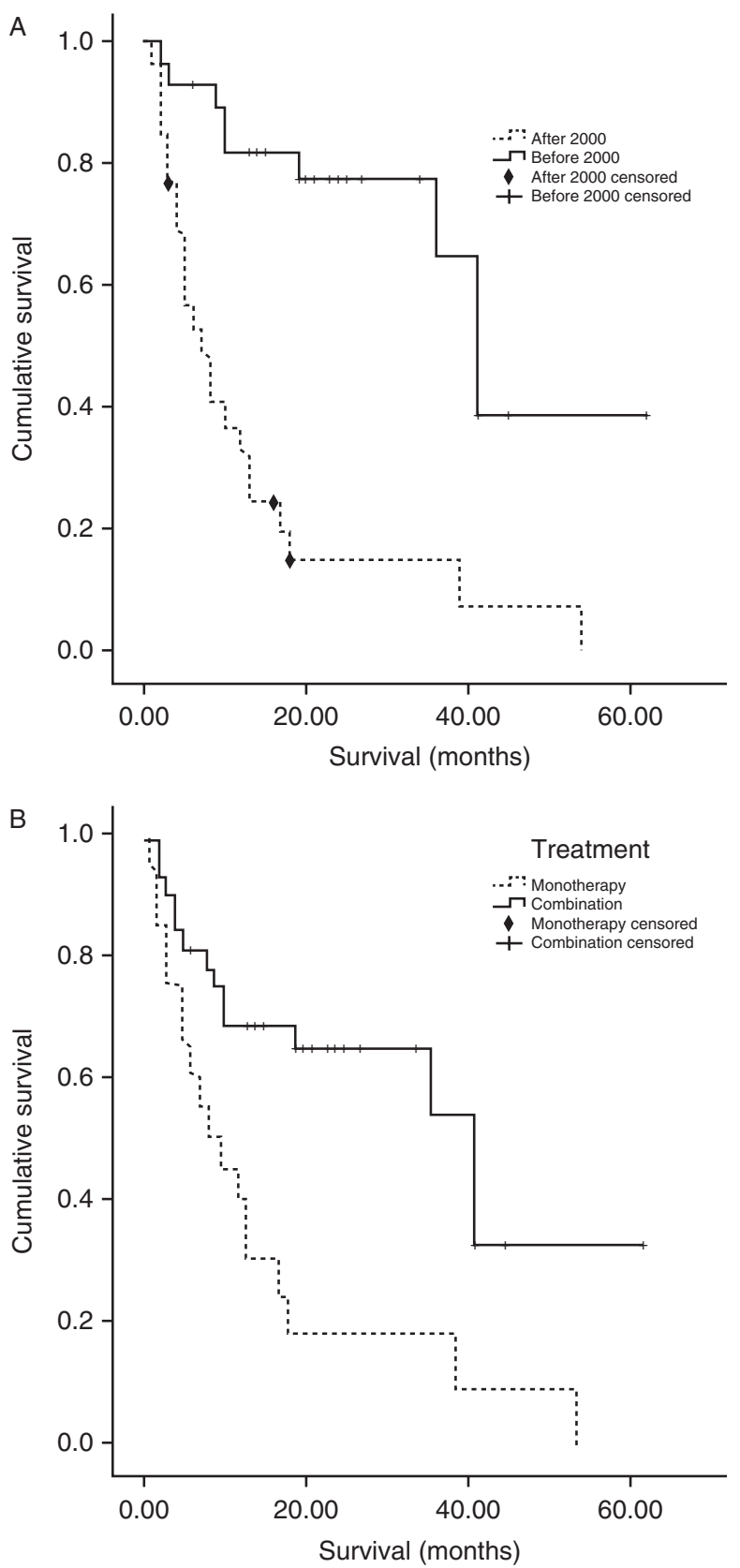

Figure 4

Survival Curves for DTC treatment: (A) before or after 2000 and (B) monotherapy vs combination. 
patients' characteristics and the evolutionary moment of departure must be very equilibrated and defined for it to be comparable.

Up to now, a treatment which increases the survival of these patients has not been developed, even the cross-over in the trial may indicate that patients can be treated at more advanced stages of the disease without reducing overall survival. Otherwise, if the treatment just achieves an increase in the PFS, this must guarantee a good quality of life. The review of the referred toxicity with the chemotherapy should be cautious. The accumulated experience with these agents and the improvement in supportive care has allowed alleviation and easing of many side effects. Thus, severe cardiotoxicity by adriamycin, almost unknown in the 1970s (Gottlieb \& Hill 1974) and described in $10 \%$ of the series, has a current frequency of nearly $<0.1 \%$ when an oncological practice is performed (e.g. calculation of the cumulative dose of adriamycin, cisplatin and good hydration) (Matuszczyk et al. 2008). As for other toxicities, they are generally less frequent and current. Comparing toxicities referred to in an old study (Gottlieb \& Hill 1974) and in a modern one (Matuszczyk et al. 2008) with the same drug and doses, they results were, respectively, neutropenia $80 \%$ versus $10 \%$, alopecia $77 \%$ versus $42 \%$, nauseas and vomiting $53 \%$ versus $23 \%$, thrombocytopenia $13 \%$ versus $0 \%$, in all its grades. Taking into account that each scheme has its toxicological profile, in general, this toxicity is considered to be acceptable (Matuszczyk et al. 2008, Spano et al. 2012). One of the most concerning problems about sorafenib and lenvatinib is its toxicity (approved for the treatment of this disease because they increase PFS without affecting survival). The DECISION (Brose et al. 2014) and SELECT (Schlumberger et al. 2015) studies describe frequent and unpleasant toxicities (foot-hand syndrome $76.3 \%$ and $31.8 \%$, diarrhea $68.6 \%$ and $59 \%$, alopecia $67 \%$ and $11.1 \%$, and about $50 \%$ of patients presented rash and desquamation, asthenia, weight loss, nauseas and hypertension) as well as severe effects (the most frequent grade 3-4 toxicities: foot-hand syndrome $20 \%$ and $3.4 \%$, HTA $9.7 \%$ and $42 \%$, and about $5 \%$ and $8 \%$ for diarrhea, rash, asthenia, dyspnoea and weight loss). In addition, in the SELECT study it was reported that $97 \%$ of the cases presented side effects, $76 \%$ with toxicity greater than or equal to grade 3 and $2.3 \%$ of toxic deaths (Schlumberger et al. 2015). This toxicity seems much higher than those referred to for chemotherapy, although some may decline over time (Worden et al. 2015), with the exception of adriamycin in association with IF, a very toxic scheme with little efficacy (Argiris et al. 2008).
We considered that there is solid data that seems to confirm the efficacy of sorafenib and lenvatinib, but due to the fact that the survival increase has not been demonstrated, there is not a clear clinical benefit or a decrease in the genesis of side effects, besides having been associated with a notable increase in the cost. Therefore, chemotherapy should be studied under the right conditions, in multicentre randomized studies that select patients with well-differentiated tumours with good PS and where the primary purpose is survival with assessment of quality of life. Whether the efficacy of chemotherapy is demonstrated or not, interesting lines of research could be established that could help to improve the actual results for patients with thyroid cancer as the sequential therapy with chemotherapy and/or other drugs, among others.

\section{Conclusions}

The effectiveness of chemotherapy in well-differentiated radioiodine refractory thyroid cancer is not well established, although there is evidence that indicates it could have greater activity with modern drugs and in patients with better PS. Given the scant advance from the treatment of these patients, we considered that welldesigned studies should be performed which analyse the efficacy and security of chemotherapy treatment with more modern drugs.

\section{Declaration of interest}

The authors declare that there is no conflict of interest that could be perceived as prejudicing the impartiality of this review.

\section{Funding}

This work did not receive any specific grant from any funding agency in the public, commercial or not-for-profit sector.

\section{References}

Argiris A, Agarwala SS, Karamouzis MV \& Burmeister LA 2008 A phase II trial of doxorubicin and interferon alpha $2 \mathrm{~b}$ in advanced, nonmedullary thyroid cancer. Investigational New Drugs 26 183-188. (doi:10.1007/s10637-007-9091-2)

Benker G \& Reinwein D 1983 Results of chemotherapy in thyroid cancer. Deutsche Medizinische Wochenschrift 108 403-406. (doi:10.1055/s-20081069567)

Benker G, Hackenberg K, Hoff HG, Seeber S, Ebke J, Windeck R \& Reinwein D 1977 Combined doxorubicin and bleomycin treatment of metastasising thyroid carcinoma: results in 21 patients (author's transl). Deutsche Medizinische Wochenschrift 102 1908-1913. (doi:10.1055/ s-0028-1105595)

Published by Bioscientifica Ltd. 
Bible KC, Suman VJ, Molina JR, Smallridge RC, Maples WJ, Menefee ME, Rubin J, Sideras K, Morris JC III, McIver B et al. 2010 Efficacy of pazopanib in progressive, radioiodine-refractory, metastatic differentiated thyroid cancers: results of a phase 2 consortium study. Lancet. Oncology 11 962-972. (doi:10.1016/S1470-2045(10)70203-5)

Brose MS, Nutting CM, Jarzab B, Elisei R, Siena S, Bastholt L, de la Fouchardiere C, Pacini F, Paschke R, Shong YK et al. 2014 Sorafenib in radioactive iodine-refractory, locally advanced or metastatic differentiated thyroid cancer: a randomised, double-blind, phase 3 trial. Lancet 384 319-328. (doi:10.1016/S0140-6736(14)60421-9)

Bukowski RM, Brown L, Weick JK, Groppe CW \& Purvis J 1983 Combination chemotherapy of metastatic thyroid cancer. Phase II study. American Journal of Clinical Oncology 6 579-581. (doi:10.1097/00000421-198310000-00013)

Cabanillas ME, Brose MS, Ramies DA, Lee Y, Miles D \& Sherman SI 2012 Antitumor activity of cabozantinib (XL184) in a cohort of patients (pts) with differentiated thyroid cancer (DTC). Journal of Clinical Oncology 30 (15, supplement, ASCO Meeting Abstracts 5547).

Carr LL, Mankoff DA, Goulart BH, Eaton KD, Capell PT, Kell EM, Bauman JE \& Martins RG 2010 Phase II study of daily sunitinib in FDG-PETpositive, iodine-refractory differentiated thyroid cancer and metastatic medullary carcinoma of the thyroid with functional imaging correlation. Clinical Cancer Research 16 5260-5268. (doi:10.1158/1078-0432. CCR-10-0994)

Cohen EE, Rosen LS, Vokes EE, Kies MS, Forastiere AA, Worden FP, Kane MA, Sherman E, Kim S, Bycott P et al. 2008 Axitinib is an active treatment for all histologic subtypes of advanced thyroid cancer: Results from a phase II study. Journal of Clinical Oncology 26 4708-4713. (doi:10.1200/JCO.2007.15.9566)

Cooper DS, Doherty GM, Haugen BR, Kloos RT, Lee SL, Mandel SJ, Mazzaferri EL, McIver B, Pacini F, Schlumberger M et al. 2009 Revised American Thyroid Association management guidelines for patients with thyroid nodules and differentiated thyroid cancer. Thyroid 19 1167-1214. (doi:10.1089/thy.2009.0110)

De Besi P, Busnardo B, Toso S, Girelli ME, Nacamulli D, Simioni N, Casara D, Zorat P \& Fiorentino MV 1991 Combined chemotherapy with bleomycin, adriamycin, and platinum in advanced thyroid cancer. Journal of Endocrinological Investigation 14 475-480. (doi:10.1007/ BF03346846)

Droz JP, Schlumberger M, Rougier P, Ghosn M, Gardet P \& Parmentier C 1990 Chemotherapy in metastatic nonanaplastic thyroid cancer: experience at the Institut Gustave-Roussy. Tumori 76 480-483.

Durante C, Haddy N, Baudin E, Leboulleux S, Hartl D, Travagli JP, Caillou B, Ricard M, Lumbroso JD, De Vathaire F et al. 2006 Long-term outcome of 444 patients with distant metastases from papillary and follicular thyroid carcinoma: benefits and limits of radioiodine therapy. Journal of Clinical Endocrinology and Metabolism 91 2892-2899. (doi:10.1210/jc. 2005-2838)

Eisenhauer EA, Therasse P, Bogaerts J, Schwartz LH, Sargent D, Ford R, Dancey J, Arbuck S, Gwyther S, Mooney M et al. 2009 New response evaluation criteria in solid tumours: revised RECIST guideline (version 1.1). European Journal of Cancer 45 228-247. (doi:10.1016/j.ejca.2008.10.026)

Ferlay J, Soerjomataram I, Ervik M, Dikshit R, Eser S, Mathers C, Rebelo M, Parkin DM, Forman D, Bray F. 2015 Cancer incidence and mortality worldwide: IARC CancerBase No.11. Lyon, France: International Agency for Research on Cancer; 2013. Available from: http://globocan. iarc.fr; accessed on 18/08/2015.

Gottlieb JA \& Hill CS 1974 Chemotherapy of thyroid cancer with adriamycin. Experience with 30 patients. New England Journal of Medicine 290 193-197. (doi:10.1056/NEJM197401242900404)

Gottlieb JA, Hill CS Jr, Ibanez ML \& Clark RL 1972 Chemotherapy of thyroid cancer. An evaluation of experience with 37 patients. Cancer 3083 848-853. (doi:10.1002/1097-0142(197209)30:3<848::AIDCNCR2820300336>3.0.CO;2-2)

Hoskin PJ \& Harmer C 1987 Chemotherapy for thyroid cancer. Radiotherapy and Oncology 10 187-194. (doi:10.1016/S0167-8140(87)80004-X)
Hussein O, Karen D \& Zidan J 2013 Cisplatin based chemotherapy in patients with advanced differentiated thyroid carcinoma refractory to I131 treatment. Indian Journal of Medical and Paediatric Oncology 34 234-237. (doi:10.4103/0971-5851.125233)

Illouz F, Braun D, Briet C, Schweizer U \& Rodien P 2014 Endocrine sideeffects of anti-cancer drugs: thyroid effects of tyrosine kinase inhibitors. European Journal of Endocrinology/European Federation of Endocrine Societies 171 R91-R99. (doi:10.1530/EJE-14-0198)

Leeper RD \& Shimaoka K 1980 Treatment of metastatic thyroid cancer. Journal of Clinical Endocrinology and Metabolism 9 383-404. (doi:10.1016/S0300-595X(80)80040-5)

Matuszczyk A, Petersenn S, Bockisch A, Gorges R, Sheu SY, Veit P \& Mann K 2008 Chemotherapy with doxorubicin in progressive medullary and thyroid carcinoma of the follicular epithelium. Hormone and Metabolic Research 40 210-213. (doi:10.1055/s-2008-1046781)

Miller AB, Hoogstraten B, Staquet M \& Winkler A 1981 Reporting results of cancer treatment. Cancer 47 207-214. (doi:10.1002/1097-0142 (19810101)47:1 <207::AID-CNCR2820470134>3.0.CO;2-6)

National Comprehensive Cancer Network. Thyroid Carcinoma (version 2.2013). Available from: http://www.nccn.org/professionals/ physician_gls/pdf/thyroid.pdf. Accessed November 5, 2013.

Pacini F, Schlumberger M, Dralle H, Elisei R, Smit JW, Wiersinga W \& European Thyroid Cancer Taskforce 2006 European consensus for the management of patients with differentiated thyroid carcinoma of the follicular epithelium. European Journal of Endocrinology/European Federation of Endocrine Societies 154 787-803. (doi:10.1530/eje.1.02158)

Poster DS, Bruno S, Penta J, Pina K \& Catane R 1981 Current status of chemotherapy in the treatment of advanced carcinoma of the thyroid gland. Cancer Clinical Trials 4 301-307.

Santini F, Bottici V, Elisei R, Montanelli L, Mazzeo S, Basolo F, Pinchera A \& Pacini F 2002 Cytotoxic effects of carboplatinum and epirubicin in the setting of an elevated serum thyrotropin for advanced poorly differentiated thyroid cancer. Journal of Clinical Endocrinology and Metabolism 87 4160-4165. (doi:10.1210/jc.2001-011151)

Scherübl H, Raue F \& Ziegler R 1990 Combination chemotherapy of advanced medullary and differentiated thyroid cancer. Phase II study. Journal of Cancer Research and Clinical Oncology 116 21-23. (doi:10.1007/BF01612635)

Schlumberger MJ 1999 Diagnostic follow-up of well-differentiated thyroid carcinoma: Historical perspective and current status. Journal of Endocrinological Investigation 22 (Suppl 11) 3-7.

Schlumberger M \& Parmentier C 1989 Phase II evaluation of mitoxantrone in advanced non anaplastic thyroid cancer. Bulletin du Cancer $\mathbf{7 6}$ 403-406.

Schlumberger MJ, Elisei R, Bastholt L, Wirth LJ, Martins RG, Locati LD, Jarzab B, Pacini F, Daumerie C, Droz JP et al. 2009 Phase II study of safety and efficacy of motesanib in patients with progressive or symptomatic, advanced or metastatic medullary thyroid cancer. Journal of Clinical Oncology 27 3794-3801. (doi:10.1200/JCO.2008.18.7815)

Schlumberger M, Tahara M, Wirth LJ, Robinson B, Brose MS, Elisei R, Habra MA, Newbold K, Shah MH, Hoff AO et al. 2015 Lenvatinib versus placebo in radioiodine-refractory thyroid cancer. New England Journal of Medicine 372 621-630. (doi:10.1056/NEJMoa1406470)

Sherman SI 2010 Cytotoxic chemotherapy for differentiated thyroid carcinoma. Journal of Clinical Oncology 22 464-468. (doi:10.1016/j.clon. 2010.03.014)

Sherman SI, Wirth LJ, Droz JP, Hofmann M, Bastholt L, Martins RG, Licitra L, Eschenberg MJ, Sun YN, Juan T et al. 2008 Motesanib diphosphate in progressive differentiated thyroid cancer. New England Journal of Medicine 359 31-42. (doi:10.1056/NEJMoa075853)

Sherman SI, Jarzab B, Cabanillas ME, Licitra LF, Pacini F, Martins R, Robinson D, Ball D, McCaffrey J, Shah MH et al. 2011 A phase II trial of the multitargeted kinase inhibitor E7080 in advanced radioiodine (RTI)-refractory differentiated thyroid cancer (DTC). Journal of Clinical Oncology 29 (suppl; ASCO Meeting Abstracts 5503). 
Shimaoka K, Schoenfeld DA, DeWys WD, Creech RH \& DeConti R 1985 A randomized trial of doxorubicin versus doxorubicin plus cisplatin in patients with advanced thyroid carcinoma. Cancer 56 2155-2160. (doi:10.1002/1097-0142(19851101)56:9<2155::AID-CNCR $2820560903>3.0 . \mathrm{CO}$;2-E)

Spano JP, Vano Y, Vignot S, De La Motte Rouge T, Hassani L, Mouawad R, Menegaux F, Khayat D \& Leenhardt L 2012 GEMOX regimen in the treatment of metastatic differentiated refractory thyroid carcinoma. Medical Oncology 29 1421-1428. (doi:10.1007/s12032-011-0070-2)

Williams SD, Birch R \& Einhorn LH 1986 Phase II evaluation of doxorubicin plus cisplatin in advanced thyroid cancer: a Southeastern Cancer Study Group Trial. Cancer Treatment Reports 70 405-407.
Worden F, Fassnacht M, Shi Y, Hadjieva T, Bonichon F, Gao M, Fugazzola L, Ando Y, Hasegawa Y, Park do J et al. 2015 Safety and tolerability of sorafenib in patients with radioiodine-refractory thyroid cancer. Endocrine-Related Cancer 22 877-887. (doi:10.1530/ ERC-15-0252)

Young H, Baum R, Cremerius U, Herholz K, Hoekstra O, Lammertsma AA, Pruim J \& Price P 1999 Measurement of clinical and subclinical tumour response using $\left[{ }^{18} \mathrm{~F}\right]$-fluorodeoxyglucose and positron emission tomography: review and 1999 EORTC recommendations. European Organization for Research and Treatment of Cancer (EORTC) PET Study Group. European Journal of Cancer 35 1773-1782. (doi:10.1016/S09598049(99)00229-4)

Received in final form 20 October 2015 Accepted 26 October 2015 